\title{
ORDEN Y AMBIGÜEDAD EN LA FORMACIÓN TERRITORIAL DEL RÍO DE LA PLATA A FINES DEL SIGLO XVIII*
}

\author{
Guillermo Wilde \\ Universidad de Buenos Aires - Argentina
}

Resumen: Por mucho tiempo la heterogénea población que habitaba la región Río de la Plata, en las fronteras entre España y Portugal, hacia fines del siglo XVIII fue asociada con la barbarie. Con el fin de homogeneizar a esta población y ajustar su comportamiento a las leyes indianas, la monarquía española implementó varias políticas de control. Sin embargo, en el corto plazo estas políticas no lograron modificar las prácticas económicas, políticas y simbólicas de esta población ni su débil percepción del Estado. Por el contrario, los actores locales mantuvieron sus dinámicas relativamente autónomas hasta casi la mitad del siglo XIX. Este artículo analiza la contradicción entre las representaciones del Estado sobre esos actores locales, construidos como "alteridad", y las dinámicas concretas que los caracterizaban, sus percepciones del territorio y el Estado, y sus estrategias para evadir los controles de las autoridades oficiales.

Palabras clave: Félix de Azara, gauchos, guarani, mestizaje.

Abstract: For a long time, the heterogenous population that inhabited the Rio de la Plata Region, in the borderlands of Spain and Portugal, toward the end of 18th Century, was associated to barbarism. To make that population homogenous and to adjust its behavior to indigenous Law, the Spanish Monarchy carried out several policies of control. However, in a short term these policies were neither able to modify the economic, political and symbolic practices of that population, nor were they able to weaken the perception this population had of the State. On the contrary, local actors kept their own dynamics until almost the first half of the 19th Century.

\footnotetext{
* La presente investigación cuenta con el apoyo de subsidios CONICET y UBACYT. Su redacción pudo desarrollarse en el marco una estancia doctoral en la Universidad de Hamburgo subsidiada por DAAD. Agradezco a Eduardo Neumman amables comentarios y sugerencias bibliográficas. La ortografía del siglo antigua, excepto las citas en lengua portuguesa, ha sido modernizada en este artículo con el fin de facilitar la lectura.
}

Horizontes Antropológicos, Porto Alegre, ano 9, n. 19, p. 105-135, julho de 2003 
This paper analyses the contradiction between State representations of local actors and the concrete dynamics that characterized them, their perceptions of territory and State, and their strategies for avoiding control by official authorities.

Keywords: Félix de Azara, gauchos, Guarani, crossbreeding.

It has often been said that the savage or the primitive was the alter ego the West constructed for itself. What has not been emphasized is that this Other was a Janus, of whom the savage was only the second face. The first face was the West itself, but the West fancifully constructed as a utopian projection and meant to be, in that imaginary correspondence, the condition of existence of the savage.

Michel Trouillot

La enorme gravitación que tuvieron las historias y antropologías nacionales de Paraguay, Brasil y Argentina en la producción académica del siglo XX generó una imagen excesivamente simplificada sobre el pasado colonial de la región del Río de la Plata. En principio se cometió el anacronismo de leer aquella realidad en la clave política y territorial de las modernas naciones fragmentando el análisis de los procesos de la zona en correspondencia con los límites trazados a fines del siglo XIX. Entre las naciones de la región, Argentina es probablemente la que con mayor insistencia ha apelado a estas proyecciones buscando las raíces de la argentinidad en el período colonial, como si sus contornos hubieran estado ya establecidos desde entonces. ${ }^{1}$

Tales proyecciones se basaban en la idea de una continuidad territorial entre la colonia y la república, y en la premisa sobre la existencia de límites naturales para territorios homogéneos. Al respecto hay que decir que si bien estas ideas no eran completamente ajenas al período colonial entonces sólo constituían esbozos y proyectos impracticables debido a las características económicas, políticas y culturales de la región a fines del siglo XVIII. Todavía pasarían muchos decenios hasta que los modernos Estados se

\footnotetext{
${ }^{1}$ Existe una importante cantidad de trabajos historiográficos que tratan sobre la "nación argentina" y los "argentinos" durante la "dominación hispánica". Para una perspectiva historiografíca diferente ver Chiaramonte (1997).
} 
constituyeran reelaborando parcialmente proyectos estatales y territoriales originados en ese período pero ya influidos por nuevas corrientes intelectuales (Quijada; Bernand; Schneider, 2000).

Dos orientaciones de la producción académica contemporánea han puesto en cuestión estas simplificaciones desde puntos de vista macro y micro sociológicos. La primera corresponde a los estudios que dan prioridad el espacio marítimo y refieren por ejemplo al "Sistema Atlántico", centrándose en procesos económicos, políticos y culturales que conectan ciudades y puertos de Europa, América y Asia. La segunda consiste en el análisis de las prácticas y percepciones de los actores locales que habitaban en los bordes de los imperios ibéricos y que permanentemente burlaban los controles que les imponía el Estado. Ambas orientaciones, de cierto modo complementarias, superan las perspectivas nacionales y brindan un panorama complejo de las transacciones y procesos de este período. También cuestionan los conceptos tradicionales de territorialidad muchas veces aceptados de manera acrítica. ${ }^{2}$ Una preocupación emergida especialmente de la segunda orientación es describir y comprender las experiencias que los actores locales poseían del Estado en una época en que no alcanzaba a definirse una esfera política autónoma. Este es un problema fundamental en el análisis del período y la región que competen al presente trabajo. ${ }^{3}$

Vale la pena empezar por una breve síntesis del contexto. Desde aproximadamente la segunda década del siglo XVIII, la corona española se embarcó en un conjunto de reformas administrativas en sus dominios americanos con el fin de imponer su presencia política y aumentar los ingresos

\footnotetext{
${ }^{2}$ Ejemplos representativos para la primera orientación son Pietschmann (2002), Alencastro (2000) y Schwartz (1994) entre otros. Para la segunda existen diferentes vertientes que no pueden resumirse en una nota. Realizamos una síntesis en Lorandi y Wilde (2000). Los trabajos referidos a la problemática de la frontera también pueden incluirse en esta orientación. En perspectiva antropológica es ineludible el trabajo clásico de Barth (1998). Para el contexto colonial americano existe abundante producción a partir de los años 80 (Ver Weber, 1998, y una síntesis de la bibliografía y discusiones en Ratto, 2001). En los últimos años ha emergido nuevamente la problemática del mestizaje como enfoque de las interacciones y los "pasajes" de actores entre diferentes universos socioculturales (Ares Queija; Gruzinski, 1997; Boccara; Galindo, 1999; Gruzinski, 1999; Gruzinski; Wachtel, 1996).

${ }^{3}$ Incluso una importante cantidad de trabajos sobre la historia rural del Río de la Plata ha tendido a provincializar procesos muy dinámicos de actores y población parcelando el análisis de los circuitos regionales más amplios. Por otra parte, la mayor cantidad de aproximaciones se enmarcan en la historia económica recibiendo escasa atención la dimensión cultural. Ver discusiones en Saguier (1991) y Garavaglia y Gelman (1995).
} 
del fisco. El peso económico de la región del Río de la Plata había crecido considerablemente a partir de las actividades comerciales del puerto de Buenos Aires y los síntomas de debilidad de los órganos centrales de poder se manifestaban en la creciente participación de los criollos en los cabildos $\mathrm{y}$ audiencias, el aumento de la presencia de portugueses e ingleses en las redes comerciales y la amenaza de ataques a las ciudades y villas de la región por parte de numerosos grupos indígenas no controlados. Las reformas perseguían fines políticos, económicos y militares pero sobre todo formulaban un proyecto sociocultural de mediano plazo que buscaba definir súbditos homogéneos sobre la base de prácticas consideradas sinónimo de "civilidad" como la agricultura, la industria y el comercio. ${ }^{4}$

Con estas medidas se incrementó la tensión entre el discurso y la política oficial, de carácter homogeneizador, y la situación concreta de la población que tendía a la creciente heterogeneidad sociocultural. De manera esquemática puede concebirse esa tensión en términos de dos "paradigmas" contrapuestos. El primero está representado por un conjunto de mecanismos discursivos de clasificación y construcción de diferencias socioculturales que intentaban dar orden a una realidad heterogénea y aplicar posteriormente políticas de asimilación. El segundo paradigma, que enmarca el comportamiento de la "población de la campaña", definía estratégicamente espacios de movilidad y ambigüedad que rompían las categorizaciones fijas y eluden los controles del Estado.

En este trabajo me propongo analizar los mecanismos internos de esos dos paradigmas. En la primera parte me centro en el discurso del Estado

\footnotetext{
${ }^{4}$ Existe abundante bibliografía sobre las llamadas "Reformas borbónicas" en diferentes lugares de América. Para un abordaje general ver Bakewell (1998). Entre las reformas más importantes de la región cabe destacar la creación del virreinato del Río de la Plata en 1776, la reglamentación para el libre comercio de 1778 y la implementación del Régimen de Intendencias en 1782. La elite criolla fue despojada de una importante cuota de poder a favor de los peninsulares tanto en la administración como la justicia y la Iglesia. Se suprimió la influencia de las principales familias y se controló a las audiencias. Se dio nuevo impulso a la expansión marítima y se aumentó la presencia militar en diversas regiones de América. Como parte del programa de reformas, el Estado también adquiría un rol preponderante en asuntos religiosos que hasta entonces habían estado fuera de su competencia. En esto debe destacarse la influencia de las corrientes regalistas (Hera, 1992). En este contexto se puede comprender la expulsión de los jesuitas (en 1767), orden que había adquirido influencia considerable en toda América y cuya fidelidad incondicional al papado era vista como un escollo para la ampliación de poderes de la corona.
}

Horizontes Antropológicos, Porto Alegre, ano 9, n. 19, p. 105-135, julho de 2003 
sobre la diferencia sociocultural tomando como ejemplo el caso de Félix de Azara y su obra Geografía Física, que incluyo en un género textual denominado "etnografía estatal". En la segunda parte me detengo en el análisis de la dinámica concreta de los actores de la campaña y sus cuestionamientos de los esquemas que les impone el discurso y las políticas hegemónicas. Dedico especial atención al caso de los guaraní de los treinta pueblos misioneros que habían fundado los jesuitas y sus interacciones con otros actores de la campaña.

\section{Las "etnografías estatales" y las fronteras de la civilidad}

La etapa final del siglo XVIII, marca un punto de inflexión en el discurso y la política respecto de la población indígena americana. De un modelo claramente identificado con la segregación se pasó a la promoción abierta de las ideas y políticas de asimilación. Un ejemplo relevante para la región del Paraguay y Río de la Plata son los pueblos guaraní misioneros fundados por los religiosos de la Compañía de Jesús a principios del siglo XVII. Inmediatamente después de la expulsión de la orden (1767), la corona española implementó sobre esos pueblos un conjunto de disposiciones que incentivaban la adquisición de hábitos y valores culturales españoles. Esas disposiciones trataban de adaptarse a los importantes cambios que había sufrido el "espacio guaraní-misionero" como resultado de las migraciones e interacciones con nuevos actores (Maeder, 1992; Poenitz; Poenitz, 1993; Wilde, 1999, 2001). De esas interacciones surgieron nuevas categorías de pertenencia sociocultural que ponían en jaque las clásicas divisiones de "castas" impuestas por la legislación indiana. Esto obligó a la corona española a rediseñar su política respecto de la población americana en un intento por crear nuevos súbditos que se ajustaran al canon definido por los valores de la ilustración. Así fue formalizándose un paradigma asimilacionista que buscaba diluir las rígidas distinciones que la misma legislación había impuesto en el siglo XVII.

Ello también exigió un cambio en los portavoces del discurso sobre el "otro", una secularización de los mecanismos de construcción de la diferencia sociocultural por parte del Estado. Desde la primera época de la conquista, los religiosos habían ocupado un rol central en la discusión sobre la condición del "indio", convirtiéndose en el centro de los debates jurídicos 
en los doctos cenáculos de las universidades de donde derivaban ideas posteriormente al Consejo de Indias. Supuestamente, las conclusiones de las eruditas discusiones acerca de los límites de la alteridad se aplicaban así al terreno práctico mediante la legislación. Pero hacia fines del XVIII, los teólogos de las órdenes regulares fueron gradualmente reemplazados por intelectuales liberales y monárquicos con clara idea del rol que debía ocupar el Estado en los asuntos de las colonias. ${ }^{5}$

Estos intelectuales jugaron un papel importante en las políticas encaradas por los borbones. Fueron en muchos casos los encargados de redefinir nada menos que la concepción misma de la conquista en concordancia con las exigencias políticas y económicas del momento. Intentaron construir una nueva "mirada imperial" basada en los principios universales de la "razón" y el "progreso". La metáfora de la "mirada" no es del todo caprichosa en el sentido de que el método por excelencia en esa empresa fue la observación, la clasificación y la comparación de entidades cognocibles y manipulables.

En efecto, a partir de la segunda mitad del XVIII se impulsaron expediciones de reconocimiento por toda América y de ellas surgiría un tipo particular de texto que se impondría con el paso de las décadas, el "relato de viaje" (Anes, 1969, [s.d.]; Pratt, 1997; San Pío, 1992). Esos textos tenían como objetivo definir los límites de la otredad americana y de manera simultánea establecer representaciones más o menos estables de la identidad peninsular. Ambas operaciones se encuentran muy presentes en la voz de los funcionarios coloniales de la época que realizaron viajes por América, efectuaron descripciones y propusieron políticas de Estado.

Las sucesivas expediciones científicas y partidas demarcatorias que España destina en gran escala a la demarcación de los límites con Portugal, intentaban también poner orden a una situación considerada caótica. Así, los expedicionarios instrumentaban nociones naturalistas para la delimitación de "fronteras" geográficas y humanas. Se trataba de un conocimiento abarcativo que bajo la amplia denominación de "Historia Natural" aglutinaba muchas ramas del saber, desde la geografía hasta la botánica y

\footnotetext{
${ }^{5}$ Para un exhaustivo análisis histórico antropológico de las ideas sobre la alteridad americana, los debates doctrinales en torno del "indio" y las ideas sobre los imperios ibéricos es una referencia obligada la obra de Anthony Pagden (1982, 1990, 1995).
} 
la historiografía. El tipo particular de texto que resultaba de este conocimiento se acercaba también a las etnografías modernas en su propósito de describir "científicamente" la diferencia sociocultural. Y si bien hay que señalar que muchos de estos textos a veces expresaban intereses individuales de quienes los producían, en el mediano plazo se convertían en instrumentos para políticas de Estado. ${ }^{6}$

Las "etnografías estatales" legitimaban los intereses y la acción del Estado por medio de la exposición de un conocimiento que era considerado puro. En ellas el discurso sobre la diferencia era revestido de una aparente neutralidad universalista. Bien entendido que ésta particular forma de "ver" al otro no estaba aislada de la situación socio-económica y política más general. El comercio Atlántico se encontraba en plena expansión y era un imperativo para España actuar simbólicamente sobre sus dominios coloniales para reforzar la idea de una monarquía absoluta. Los nuevos métodos de conocimiento (clasificación, jerarquización, comparación) se convirtieron por tanto en herramientas para el ejercicio del poder. Las "etnografías estatales" permitirían mediante la descripción ordenar la diferencia o establecer los límites entre un adentro y un afuera inscripto en la cultura. En esa operación construían su propio lugar como "acultural", o si se prefiere, "metacultural" (Urban, 1992). ${ }^{7}$

\footnotetext{
${ }^{6}$ Podríamos decir, haciéndonos eco de los análisis de Mary Louis Pratt, que las "Etnografías Estatales" eran textos destinados a construir la alteridad tomando la forma de la "anticonquista". La autora define la "anticnquista" como un conjunto de "estrategias de representación por medio de las cuales los sujetos burgueses europeos tratan de declarar su inocencia en el mismo momento en que afirman la hegemonía europea." (Pratt, 1997, p. 27). La "anticonquista" a través de sus protagonistas, que podemos llamar "agentes estatales", tiene la función aparentemente inocente de "ver" encarnando unos "ojos imperiales" que "pasivamente observan y poseen" (Pratt, 1997, p.27).

${ }^{7}$ En este trabajo utilizaré los términos "cultura" y "naturaleza" como categorías analíticas pero hay que destacar que ese dualismo, constitutivo de la modernidad, estaba todavía formulándose en la época de Azara. En el Diccionario de Autoridades de 1726 "cultura" aparece definida como la "labor del campo o el ejercicio en que se emplea el labrador" y metafóricamente el "cuidado y aplicación para que algúna cosa se perficione: como la enseñanza en un joven, para que pueda lucir su entendimiento". También alude al culto "en el sentido de reverencia o adoración" (DA, 1963, p. 699). En cuanto al término "naturaleza", tiene una diversidad de significados. Refiere a "la esencia y propio ser de cada cosa", al "agregado, orden y disposicion de todas las entidades, que componen el universo", al "principio universal de todas las operaciones naturales, è independientes del artificio", a "la virtud, calidad, o propiedad de las cosas". Y continúa el diccionario: "Se llama también el sexo, especialmente en las hembras", "el origen que alguno tienen en alguna ciudad o reino en que ha nacido", "naturalidad en el sentido de ingenuidad y sencillez", "temperamento de qualidades en el cuerpo del animal" (DA, 1963). Como puede notarse, muy pocas de estas definiciones se acercan a la versión "científica" que se impondrá a fines del siglo XIX.
}

Horizontes Antropológicos, Porto Alegre, ano 9, n. 19, p. 105-135, julho de 2003 
La obra Geografía Física y Esférica de las Provincias del Paraguay y Misiones guaranies de Félix de Azara puede incluirse dentro de este género textual. En ella se esbozan nuevas estrategias discursivas para la construcción de diferencias socioculturales que con el tiempo se afirmarán y aplicarán a políticas concretas de Estado. Azara tuvo gran importancia en la creación de la mirada hegemónica de América del Sur española y en particular del Río de la Plata. Este funcionario tuvo además participación directa en las políticas respecto de las poblaciones nativas. A partir de su figura es posible hacerse una idea del singular perfil de determinados funcionarios ibéricos de la época que, preservando determinados valores mediterráneos y católicos, promovían reformas de corte ilustrado (Azara, 1994). Azara había formado parte de la liberal Sociedad Económica Aragonesa de Amigos del País. En 1780 es designado comisionado en la "Expedición a América Meridional" dirigida por José Varela y Ulloa, que tenía como propósito efectuar una delimitación territorial entre los dominios de España y Portugal luego de que ambas coronas firmaran el Tratado de San Ildefonso (1777). Azara se traslada a América en 1780 como ingeniero militar de dicha expedición instalándose en Asunción, donde organiza una serie de viajes por toda la región y escribe sendas descripciones sobre los lugares visitados. ${ }^{8}$

Una parte de Geografía Física está dedicada a la descripción general, "física, política y moral", de los "países" comprendidos en las provincias del Paraguay y Misiones, y en el distrito de Corrientes. Conviene analizar la singular antropología de la región que Azara esboza en ella. Comienza por presentar una clasificación de los "habitantes", a quienes distingue en tres castas: la "española", la "india" y la "africana" de las cuales, considera, es preciso "hacer varias subdivisiones porque así lo requiere su estado físico, moral y político." (Azara, 1904, p. 350). Azara llega a los guaraní misioneros, incluidos en la segunda casta, luego de un inventario de descripciones de a momentos confusas y contradictorias. Comienza con los "indios payaguas", más adelante habla de los "indios mbayas", luego de los "guayana", retratándolos siempre de acuerdo a la talla, el aspecto físico, la

\footnotetext{
${ }^{8}$ Las actividades de demarcación se vieron demoradas por varios años, tiempo que Azara empleo para viajar y hacer descripciones. Para un perfil de la figura de Azara, puede consultarse el clásico estudio bio-bibliográfico de Julio Cesar González (1943), al igual que el "Estudio preliminar" de Azara (1994).
} 
vestimenta y las "bárbaras costumbres" desde la crianza al enlace matrimonial. Respecto de los "guayanás" dice que son "flacos, de bella estatura y proporciones, que algunos tienen ojos azules, los restantes negros: que aunque su color no pueda decirse blanco, lo es respecto a los demás indios, que son de a pie [...]" (Azara, 1904, p. 404). Continúa con los "guanás" y luego con los "lenguas" en la misma tónica. Refiriendo a la talla de los tupi y los guaraní señala que es "más baja, ridícula, cuadrada y pusilánime" (Azara, 1904, p. 402). Algunas frases, hoy vistas, son de una arbitrariedad y vaguedad sorprendentes, por ejemplo, afirma de los tupi que "cuentan [los que] los han visto que el color es de indio." (Azara, 1904, p. 403). ${ }^{9}$

Azara también abunda en comparaciones. Sugiere que algunas descripciones son intercambiables. Por ejemplo, que la "descripción de los LENGUAS debe servir sin quitar ni poner para los GUAYCURÚ, ENIMAGÁ y MACHICUY" (Azara, 1904, p. 394, en mayúscula en el original). Algo similar afirma respecto de los guaraníes algunos de cuyos rasgos los "aproximan" a los Minuanes y Charruas, mientras otros los mantienen alejados de estos (Azara, 1904, p. 405). Respecto de los guaraníes monteses (caaguas o cainguá) dice que son lo mismo que la segunda clase de guayaná "aunque tienen diverso nombre" (Azara, 1904, p. 407). Afirma también que una segunda clase de guayaná, "[...] es indubitablemente guaraní porque así lo justifican plenamente su idioma, su baja, triste cuadrada y fea figura que regulo de 5 pies y 9 pulgadas españolas." (Azara, 1904, p. 406). Y las descripciones continúan en el mismo tono. ${ }^{10}$

Detrás de la vaguedad y confusión palmarios en las descripciones de Azara prevalece una intención política clara de ordenar la diferencia por medio de las operaciones de nominación, clasificación y comparación. Operaciones que si bien no eran nuevas en el proceso de conquista ahora

\footnotetext{
${ }^{9}$ Este tipo de descripciones encuentran explicación parcial, por unn lado, en un contexto en que todavía no se había impuesto el paradigma de "ciencia humboldtiana" (Podgorny; Schäffner, 2000). Por otro lado, en la probablemente escasa formación de Azara como naturalista, actividad desarrollaba como "hobby" mientras esperaba resoluciones de sus superiores en relación a la demarcación con Portugal. Para una aproximación a la visión de los "ingenieros militares" ibéricos y el paradigma geográfico de fines del siglo XVIII ver Capel (1981, 1983).

${ }^{10}$ He omitido referencias a Viajes por la América Meridional de Azara (1982) pero se trata también de una obra representativa.
} 
venían legitimadas por el discurso de la "ciencia". Con frecuencia Azara apelaba como soporte para estas descripciones a la representación visual a través de mapas e ilustraciones que fijaban en el espacio físico la diferencia sociocultural (Alonso, 1994). En síntesis, Geografía Física, como obra inscripta en el género que denomino "etnografías estatales" naturaliza las representaciones de la alteridad y en ese mismo acto formula el rol legitimante de la mirada española.

En la obra de Azara pueden reconocerse básicamente tres mecanismos de naturalización de la diferencia sociocultural. El primero es la construcción de oposiciones estigmáticas en donde establece su propio lugar como el polo positivo de una oposición, mientras que el lugar del "otro" es considerado incompleto. Algunas de las oposiciones que define son adentro-afuera, racionalidad-irracionalidad, civilidad-gentilidad, limpieza-suciedad. El segundo mecanismo, íntimamente relacionado con el anterior, produce un desplazamiento de la "cultura" de los otros hacia la animalidad y la femeneidad, rasgos ya asociados en la época con la falta de racionalidad y con la "humanidad disminuida". La tercera estrategia, de universalización, es la que define el lugar de Azara como lugar metacultural o "acultural" y borra las especificidades que marcan su propio discurso como perteneciente a una sociedad y una cultura particular, la Europa ibérica de fines del siglo XVIII. ${ }^{11}$

Al referir a los "habitantes" de la región Azara destaca el hecho de que carecen de algún valor de la vida civil. Respecto de los guaraní de los pueblos misioneros señala que conocen poco el honor y la vergüenza aunque permanentemente busquen ocupar algún empleo de cabildo (Azara, 1904, p. 416). Algunas páginas antes les había comparado con los chaqueños:

También se parecen en las débiles influencias del amor que no tienen la actividad española: jamás se mueve por su estimulo la menor pendencia, ni las mujeres son premio del valor: este es un asunto tan frío como el paseo. Los pocos años, la perfección del cuerpo, la

\footnotetext{
${ }^{11}$ Para la caracterización de esta última estrategia me inspiro en parte en Greg Urban (1992) quien distingue dos modalidades de discurso sobre la cultura. Por un lado el llamado "cultura alfa", que expresa lo local y lo particular, el discurso sobre la diferencia étnica y racial. Por otro, el denominado "cultura omega" que expresa lo universal, lo racional, lo acultural. El autor refiere a estos conceptos respectivamente como cultura y metacultura. Las "Etnografías Estatales" predican sobre la cultura alfa y asumen el lugar de la cultura Omega (Cultura con mayúscula) o metacultura. De este modo se trocan en discurso universalista y desmarcan su inscripción particular en la "cultura" ilustrada de fines del siglo XVIII. Para un amplio recorrido crítico de la literatura reciente sobre procesos de construcción de alteridades ver Briones (1997).
}

Horizontes Antropológicos, Porto Alegre, ano 9, n. 19, p. 105-135, julho de 2003 
viveza, y obsequios con otras calidades tan apetecidas de nuestras mujeres andan a la par entre los indios con las canas y jorobas: cualquiera hombre es lo mismo para las mujeres, cuyos negocios, nunca prolongan un minuto la conversación. Verdad es que esto no es tan absolutamente cierto con los hombres para con las mujeres, pues aunque no riñen por ellas ni las galantean, acostumbran dar alguna preferencia no muy buscada, a las más lindas. (Azara, 1904, p. 412, destacado mío).

En este párrafo Azara define al "otro" por la carencia de "honor y vergüenza", dos valores culturales propios de la sociedad de Antiguo Régimen que proyecta universalmente como atributos necesarios de la "Humanidad". Una humanidad que si bien no exhibe abiertamente sus rasgos particulares, se encuentra inscripta históricamente en la tradición europea mediterránea y masculina. En otro párrafo en que compara a los guaraníes y los indios chaqueños Azara sutilmente inscribe las diferencias socioculturales en el plano sexual subrayando las carencias políticas y fenotípicas. Por ejemplo escribe que viven reunidos a jefes "que no lo son" y que no tienen "más pelos que en la cabeza". ${ }^{2}$ Azara llega al punto de equiparar sexualmente a algunos de los "habitantes" con los animales, como queda claro en el siguiente párrafo:

La abundancia de la casta débil o infecunda llamada albina está aquí mucho más extendida; pues no he visto pago ni pueblo donde no haya alguno, y también los he hallado entre los venados, tigres, zorros, monos, y aun entre las aves, pero no en los negros y mulatos. (Azara, 1904, p. 413).

\footnotetext{
12 "[1] as principales semejanzas se reduce a vivir bajo de esteras o malas chozas, a no sufrir más pelo que en la cabeza, a tener el mismo vestido o por mejor decir a ir casi desnudos sin sombrero ni gorro, a pintarse, emborracharse, tener las mismas armas y modo de hacer la guerra furtiva matando a los varones adultos, y cautivando y adoptando los demás, a traer barbote, a vivir reunidos a caciques o jefes, que en realidad no lo son en pequeñas partidas, a ser polígamos, ni muy carnosos, ni flacos ni enfermizos, a tener el mismo color, la cara algo plana, y las mujeres el pecho abultado, el pie y manos pequeños, escasa menstruación y rayas verticales moradas de firme en la frente: a tener todas pays o médicos y el mismo modo de curar sus dolencias, a no conocer juego de ninguna especie; a hablar poco y sólo lo preciso, y jamás conversaciones ni juntas ociosas ni familiares a cantar poco o nada, a ser inconstantes, falsas, y pedihueñas, desconfiadas, desagradecidas, ladronas y prontas para efectuar cualquiera maldad sin que se les heche de ver en el semblante, y a no conocer la vergüenza ni el honor, ni cuidar de otra cosa que de lo presente." (Azara, 1904, p. 411412, destacado mío).
} 
Tanto la posesión de gobierno como determinados atributos sexuales son construidos en el discurso de Azara como condiciones esenciales de la vida social. Subyacen a este discurso algunas premisas fundamentales de la Europa de la época sobre la "virtud", el "honor" y el "buen gobierno" conceptos para los que los intelectuales ibéricos propusieron sus propias definiciones. ${ }^{13}$

Hay que enfatizar que muchas ideas de Azara se tradujeron en políticas concretas de Estado, pero paradójicamente con objetivos claramente homogeneizadores que buscaban destruir la diferencia reconocida o inventada previamente. Las políticas más importantes en el Río de la Plata destinadas a crear homogeneidad fueron básicamente tres muy relacionadas entre sí: la definición de un territorio por medio de la demarcación de los límites con Portugal, el exterminio de la población "infiel” y el poblamiento de la "campaña". Esas políticas definían en el plano sociocultural una distinción entre un "adentro" y un "afuera". El "adentro" era concebido como un espacio homogeneo, donde eran eliminadas las fronteras étnicas que diferenciaban a los diversos grupos reducidos e "infieles" y la población criolla. El "afuera" era identificado con una alteridad equiparable con España. Frente a éste "gran otro", Portugal, la corona española podía imaginarse como cuerpo homogéneo o al menos homogeneizable. Es destacable que mientras el "adentro" se establecía en términos étnicoraciales y se apuntalaba en un canon de civilidad, el "afuera" se expresaba en términos político-administrativos. ${ }^{14}$

En conclusión, el discurso oficial del que es modelo la obra de Azara posee una contradicción intrínseca. Posee, como Jano, dos rostros: construye al otro como otro y simultáneamente define la identidad del Estado como entidad sociocultural. A partir de allí implementa dispositivos de asimilación basándose en valores universalistas. Este segundo rostro incorpora al otro como igual en apariencia, si y solo sí, se adapta a valores particulares asumidos como universales. Con esta operación los escritos derivan fluidamente de la diferencia a la asimilación, como dos polos

${ }^{13}$ Debe hacerse un estudio exhaustivo sobre las fuentes del pensamiento y las descripciones de Azara. En la época las problemáticas del "honor", la "virtud" y el "buen gobierno" eran objeto de discusión en numerosos tratados. Sobre el concepto de honor ver Maravall (1989), sobre el de virtud Coughlin (1992). Para una discusión antropológica sobre esos conceptos ver Pitt-Rivers y Peristiany (1993).

14 Este doble mecanismo de construcción de la diferencia hacia "adentro" y hacia "afuera" estaba presente también en el discurso de otros funcionarios demarcadores como Oyarbide, Alvear y Aguirre que, como Azara, produjeron sendas descripciones en diarios y memorias.

Horizontes Antropológicos, Porto Alegre, ano 9, n. 19, p. 105-135, julho de 2003 
opuestos que se atraen y se devoran. ${ }^{15}$ "Crear diferencia para asimilar" es la consigna subyacente en el discurso de las "Etnografías Estatales".

Ahora bien, ¿cuál era la actitud de los actores concretos frente a este discurso del orden y a las políticas homogeneizadoras? Para responder a este interrogante es necesario una descripción y análisis de la dinámica local de la campaña y sus lógicas interna.

\section{La génesis de categorias socioculturales ambiguas}

A principios del siglo XIX, el funcionario Gonzalo de Doblas escribía en su Disertación lo siguiente:

[...] los indios conocen ya los efectos de la libertad, y como no pueden lograr la de los mismos pueblos van a buscarla fuera de ellos, pasando a las provincias inmediatas, uniéndose en ellas comúnmente a los españoles abandonados, que con sus viciosas costumbres los pervierten y relajan, otros se mezclan con los minuanes y charrúas, viviendo entre ellos como gentiles, aumentándoles la audacia con las noticias que les suministran, pero lo peor de estas emigraciones es los muchos que se pasan a los dominios de Portugal, perdiendo el Estado estos vasallos y aumentando el poder al extranjero en aquella parte. Las jurisdicciones de Río Pardo, Puerto Alegre y Río Grande están llenas de indios de Misiones, allí han fundado pueblos con los mismos nombres que los de su naturaleza, sirviendo de reclamo a los que se desertan particularmente del Departamento de San Miguel; en ellos no están sujetos a la comunidad, son tratados en todo como los plebeyos portugueses, y esto basta para parecerlos que han mudado de naturaleza, y que no son ya aquellos que eran en sus pueblos. (Doblas, 1948, p. 32).

${ }^{15}$ En el momento mismo de la conquista encontramos ya presente esta contradicción. Desde ese primer momento se planteó el dillema de la necesidad y la imposibilidad de crear al "otro" como diferente, y por otra parte, la de incorporarlo dentro de un sistema sociocultural de dominación (Sider, 1987). 
Este párrafo no sólo ilustra una situación que ya era común en la región desde varios años antes como producto de la declinación económica de los pueblos guaraní misioneros sino que además revela la debilidad del concepto de Estado para la población de la campaña que había hecho de la fuga y la movilidad estrategias fundamentales. El mismo año que Doblas escribía este párrafo, siete de los treinta pueblos guaraní misioneros fueron ocupados por las tropas portuguesas. ${ }^{16}$ Las características de este hecho están poco estudiadas pero aparentemente la ocupación contó con el apoyo de las autoridades indígenas de los pueblos que aceptaron la protección de los portugueses. Estos venían invitándolos a pasarse a sus dominios donde se les prometían mayores comodidades. Declarada la guerra entre España y Portugal, el pueblo de San Lorenzo se ofreció a pasar a la protección portuguesa lo que fue aceptado inmediatamente por el comandante de frontera Pereira Pinto. El jefe desertor José Borges do Canto, hijo de un portugués y una mujer indígena, se ofreció a defender San Lorenzo y ocupar los otros seis pueblos que estaban descontentos del gobierno español. Canto promovió la deserción de los guaraní que disgustados con su teniente gobernador, pasaron a los dominios portugueses (Porto, 1943).

A partir de este episodio cabe preguntarse hasta qué punto el pasaje entre los dominios de Portugal y España constituía para los mismos sujetos un cambio de "naturaleza" como quería verlo el funcionario Doblas. ¿Estaban estos inspirados en la misma noción de territorialidad que marca el discurso de Doblas? ¿Cuál era la lógica de sus movimientos y estrategias? ¿Cómo percibían al Estado?

Hasta el momento sabemos muy poco sobre estas percepciones. Informes como el de Doblas y otros funcionarios son insuficientes para tener una idea precisa del significado del comportamiento y las experiencias de los sujetos de la campaña. No obstante, algunos indicios pueden encontrarse en otras fuentes del período, como las "sumarias criminales". Si bien la tónica general de estos documentos judiciales no escapa a la visión estigmática del relato dominante, algunos testimonios presentan descripciones de dinámicas concretas, y a veces también la voz de los actores, por así decir, "subalternos". Veamos un caso.

${ }^{16}$ Esos pueblos, ubicados al oriente del Río Uruguay, eran los mismos que cincuenta años antes habían dado origen a la llamada "Guerra Guaranítica".

Horizontes Antropológicos, Porto Alegre, ano 9, n. 19, p. 105-135, julho de 2003 
A fines de 1799, una mujer llamada María Isabel Franco fue raptada en la campaña por un grupo de "ladrones". Algunos meses después, la mujer fue rescatada y pudo hacer declaraciones ante la justicia en la que relató los hechos en detalle. Dijo que los "foragidos" asesinaron a su marido y que uno de ellos entró a la casa donde se encontraba y, agarrándola de la mano, empezó a sacar todo lo que encontraba repartiéndolo entre los que se habían quedado en la puerta. Luego la condujeron al sitio donde había quedado el cadáver de su marido ejecutado por el líder del grupo, el "Indio Cristiano" Josef Ignacio. La mujer pudo ver el cuerpo de su difunto marido desnudo, amarrado y herido. En su presencia le arrancaron el "chuzo" con que tenían clavado el cuerpo contra el suelo por el costado derecho. Poco antes la mujer había podido oir que uno de hombres ordenaba en castellano a su marido todavía vivo que se entregase, y luego Josef Ignacio, el "indio cristiano", "amonestaba a los demás no agujereasen la ropa para matarlo que se ensuciaba con la sangre". Frente al cadáver de su marido, el tal Josef Ignacio relató a la mujer que él era "Cristiano como ella y casado en el Caneló con una Mulata Esclava de Gregorio Bordon por la cual había hecho una muerte siendo esa la causa de verse metido entre los Infieles", que ese era el "peor cuchillo" que tenían los cristianos. También le aseguró que antes de los avances "bombeaba" estancias y que por esos días había estado también en la de Don Manuel Pérez, del otro lado del Río Negro.

En esta conversación Josef Ignacio indagó a María Isabel Franco sobre las "Mujeres de las poblaciones inmediatas" a lo que ella contestó que no estaban. Luego de esto fue llevada al corral donde la alzaron en un Caballo en pelo con el propósito de volver a los Toldos. Como no sabía andar, la mujer cayó al suelo y un "Indio Minuan" quiso castigarla pero lo impidió José Ignacio quien la alzó a las ancas del mismo "indio" que la había sacado de su casa. Al poco andar la mujer prorrumpió en llantos y fue maltratada con muchos golpes. De allí marcharon hasta la otra parte del Queguay y pasaron por una estancia destruida en la que sólo quedaba el corral. La mujer supo por Josef Ignacio que a la ida ellos mismos habían quemado la casa y a su cuidador adentro. Pasaron la noche en el corral y al día siguiente marcharon hasta una toldería cercana. Sobre la marcha encontraron unos "corredores de ganado" a quienes despojaron de los caballos y mataron a dos "que alcanzaron sin parar de caminar de día y noche hasta internarse mucho en los Campos Desiertos" (Mariluz Urquijo, 1952, p. 19). 
El detallado relato de la mujer permite reconstruir algunas de las características de actores que eran categorizados de manera vaga y estigmática en la documentación oficial. Entre esas características cabe destacar la permanente movilidad y prácticas generalmente etiquetadas por la historiografía bajo el rótulo de "violencia" como el saqueo de puestos de estancias, la matanza, la práctica del "robo" de ganado y el cautiverio de mujeres. La declarante da indicios de que se trataba de un grupo de "indios minuan", pero la referencia a los "indios cristianos" puede estar revelando la activa participación de guaraníes de los pueblos misioneros. En efecto, es muy probable que Josef Ignacio fuera un guaraní misionero desertor que conocía bien el funcionamiento de los pueblos, villas y estancias de la zona, conocimiento en el que residía su autoridad. Es interesante resaltar que este personaje se preocupa por diferenciarse del resto de los miembros del grupo ante los ojos de la mujer. Para ello apela a su condición y status de cristiano y a ciertos cuidados con la mujer que contrastan con la brutalidad de los demás hombres.

Sin embargo, el rasgo saliente de la actitud de Josef Ignacio es que escapa a las categorizaciones oficiales fijas. No sólo ha evitado vivir de manera "estable" y segregada en un pueblo cristiano sino que se ha casado con una mulata esclava y se ha mezclado con los "infieles". Aún así, sigue autoidentificándose como "indio cristiano" y de ese modo quiere que lo identifiquen. ¿Por qué actúa este personaje de esta forma? ¿Conlleva su actitud algún tipo de conflicto de identidades o creencias? Muy difícil saberlo. Aparentemente Josef Ignacio puede convivir con ambas identidades. Por de pronto pareciera situarse en un espacio de ambigüedad muy útil en la medida que le permite "entrar" y "salir" permanentemente de su condición de "indio cristiano", maniobrando según sean sus conveniencias. ${ }^{17}$

Existieron muchos casos como este en el período comprendido entre 1770 y 1805 favorecidos por circunstancias económicas y político-administrativas más generales que movilizaron crecientes contactos e intercambios poblacionales (Wilde, 2001). Los guaraní misioneros fugitivos fueron actores centrales en la creación de espacios de "ambigüedad" y confusión

\footnotetext{
${ }^{17}$ A una situación parecida alude Maria Regina Celestino de Almeida en referencia a los "indios aldeanos" de Niteroi en la región de Rio de Janeiro (Celestino de Almeida, 2000, de próxima publicación). La autora muestra cómo estos grupos asumen más de una identidad en conformidad a la situación que les toca enfrentar.
}

Horizontes Antropológicos, Porto Alegre, ano 9, n. 19, p. 105-135, julho de 2003 
en los que se diluía temporariamente la lealtad hacia la corona española y la condición de cristiano. Para esto con frecuencia se mezclaban con otros grupos desarraigados de la campaña, entre los que sobresalen los "infieles", los portugueses y los españoles desertores. Al respecto existe mucha información en las fuentes posteriores a la expulsión de los jesuitas.

Una carta escrita hacia el final de la década de 1770 por el corregidor guaraní y otros representantes del Pueblo de Yapeyú, señala que las estancias y Pueblos están combatidos de los "charruas, minuanes asociados de los guaderíos, portugueses y españoles" (AGN IX.39.5.5). Por la misma época otro informe observa en relación con las partidas de salteadores que se componen de un número elevado de indígenas, cerca de mil, que viven en las toderías de los minuan "incluyendo en este número los naturales guaraníes que se han desertado y se hallan abrigados con ellos, el de varios españoles, portugueses, mulatos, y negros que se han incorporado a aquella nación" (AGN IX.39.5.5).

La relación de los guaraní misioneros con los "infieles" ha sido generalmente caracterizada como hostil pero fue en realidad mucho más ambigua y compleja de lo que se supone. Se trataba de una relación generalmente inestable que alternaba momentos de hositlidad con momentos amistad e intercambio muchas veces motivados por relaciones de parentesco. En 1768, el nuevo cura franciscano del pueblo misionero de Yapeyú informa de la llegada de 14 "infieles" al pueblo y que se aproximan tres caciques "bojanes" y "minuanes" para convertirse. Un mes y medio más tarde otro grupo minuan se acercó al pueblo de San Borja y a la estancia de San Nicolás con la intención de cristianizarse pidiendo gratificaciones a cambio (Ortiz [7-11-1768]; Zavala [28-12-1768]). Al año siguiente se informa que la conversión de los minuan de Yapeyú "se ha reducido a seis varones, siete mujeres y cinco muchachos que estan en este pueblo, y el otro día se escapo uno a nado y pasó el Uruguay y se fue a los toldos [...]" (Zavala [9-2-1769]). En 1770 hay noticias de la "venida de unos indios Cainguas infieles a una estancia del pueblo de Jesús". De estos se observa que "son dóciles y se tratan de parientes" con los del pueblo (De la Granja y Alvarez [14-9-1770] Zavala [17-9-1770]).

Es posible encontrar indicios de estos contactos e intercambios en plena época jesuítica. Hacia 1760 el jesuita Bernardo Nusdorffer escribe que ha sido reunida una gran cantidad de familias, cerca de 88 almas, la mayor parte provenientes del pueblo de San Borja. Observa que "venían ya casi todos desnudos, vestidos con cueros de venados, a modo de infieles, y los niños sin 
bautismo. Los más eran del pueblo de San Borja, fruto infeliz de los alborotos de esta transmigración" (Nusdorffer, 1971, p. 163). Eran conocidas las fluidas relaciones que tenían los del pueblo de San Borja con población "infiel" que habitaba en las cercanías. Algunos años después el jesuita Segismundo Asperger refería al pueblo de minuanes llamado Jesús María, creado hacia principios de siglo en las tierras de San Borja. Informaba que no se había multiplicado nada porque muchos habían muerto, "y los pocos otros se ivan paseando á ver á sus parientes, llevando consigo algunos Guaranis de San Borja consigo como ya amigos suyos". Debido a estas deserciones, agrega el jesuita, ya en el año de 1721 no hubía "Guenoas" convertidos en ese pueblo (apud Poenitz, E., 1985, p. 10). ${ }^{18}$

La evidencia de una receptividad mutua de "indios reducidos" y "noreducidos" lleva, por un lado, a cuestionar seriamente la visión del supuesto aislamiento de los guaraní misioneros, y por otro, a reflexionar sobre un sentido particular para la categoría "infiel" entre los actores locales que se distanciaba del que imponían las fuentes oficiales. Esa categoría, más que referir a un grupo particular parecía representar en el imaginario de los actores locales un espacio semántico de "no pertenencia", de movilidad y de oposición al orden establecido, o, más importante aún, de lealtades flexibles. Este tipo de categoría, como la de "gaucho" poseían mayor eficacia que la pertenencia fija a un Estado. La lealtad basada en lazos personales concretos resultaba más eficaz y además facilitaba permanentes pasajes entre los dominios de ambas coronas. Un ejemplo en este sentido es el ya citado caso de Borges do Canto durante la ocupación portuguesa de los siete pueblos orientales en 1801. Otro ejemplo más temprano aparece en un relato de 1770 sobre el choque de un grupo de vaqueros de los pueblos misioneros con una partida de portugueses que los emboscaron. En esa ocasión los portugueses dijeron a los misioneros: "Vosotros sois castellanos, y los castellanos han empobrecido a nuestra tropa y así vosotros nos lo han de pagar, que también son castellanos, hoy han de morir todos". Un oficial de los portugueses evitó la desgracia diciendo que ya bastaba con haberles quitado los caballos, vacas y "sus cosillas", que los dejarían morir de necesidades en ese sitio. Entonces se retiraron y dos guaraní misioneros de la tropa los siguieron, uno de ellos llamado Damazo Cayupi y el otro Francisco de Borja Niayrama (Pérez [12-121770]).

${ }^{18} \mathrm{Si}$ bien el caso minuan y guenoa es paradigmatico también existe evidencia de entradas y salidas de otros grupos "infieles" en los pueblos misioneros (Wilde, 2001).

Horizontes Antropológicos, Porto Alegre, ano 9, n. 19, p. 105-135, julho de 2003 
Treinta años después, encontramos otro ejemplo de "pasaje" entre lealtades reales, en este caso en el sentido inverso. Escribe un funcionario al gobernador Lazaro de Rivera que un "cacique portugues" ha solicitado pasarse a los dominios españoles con su gente, "ha suplicado se le señalen las tierras en que aigan de establecer, pues recelan de que el Comandante Don Pedro Gracia les tratan con alguna severidad [...]" (ANA (SH) vol. 181, $\mathrm{N}^{\circ}$ 9, 1800). Se le concede este permiso y se le señalan tierras en las cercanías del Río Jejuy. Su traslado cuenta incluso con el apoyo del administrador de San Joaquín y San Estanislao (ANA (SH) vol. 181, N 9).

De las situaciones de ambiguiedad creadas por estos movimientos deben haber surgido nuevas categorías de identificación sociocultural de gran flexibilidad y adaptabilidad. No está del todo clara la procedencia del término "guaderío" o "gaucho" pero posiblemente apareció en la segunda mitad del siglo XVIII para referir a la población desarraigada de la campaña que se dedicaba a las actividades ganaderas consideradas "ilegales" y que llevaba un modo de vida que no se ajustaba al canon oficial. Las fuentes oficiales generalmente plasmaban una visión estigmática respecto de esa población utilizando el término negativamente, pero aparentemente éste se originó y difundió entre los mismos actores de la campaña. Así lo manifiesta el siguiente párrafo de Miguel de Lastarria, secretario del Virrey Avilés en 1800:

Hay hacendados que poseen mas de cinquenta leguas; y que cuentan mas de dos cientos dependientes sin oir el Santo Sacrificio de la Misa; ni asistir á concurso de fiestas ó diversiones publicas; cuyo estado de barbaridad, é indecencia he descripto distinguiendolos con el nombre que les dan de Guaderios, Gauchos y Camiluchos. Concivo que contribuiría á restituirles la sensivilidad, y substituir en ellos la decencia de modos y maneras, y lo que es mas, se mejoraran sus costumbres mediante los puntos de reunion religiosa. Por lo que convendrá que también se solemnicen las fiestas de los Santos: con esta ocasión se cortaran las barvas, se limpiaran, y procuraran vestirse; gustando despues del buen luxo; que llamo al que se encuentra en los pueblos como la Sal que sazona el alimento. (Lastarria, 1914, p. 245).

Este fragmento bien podría pertenecer a Azara o a cualquier otro funcionario ilustrado de la época ideológicamente enmarcados en el paradigma descripto en la primera parte de este trabajo. En la cita previa la oposición civilidad-incivilidad se expresa en términos de la más figurativa 
polaridad limpieza-suciedad, mostrando ante todo que la suciedad es ofensiva del orden civil (Douglas, 1991). Las autoridades locales de los cabildos empleaban términos parecidos para identificar a gran cantidad de sujetos que deambulaban por la campaña y que se dedicaban al robo de ganado. Así por ejemplo abundan en las fuentes términos como "ladrones", "fascinerosos", "malhechores", "vagos", o simplemente "gente de la campaña" cuya vaguedad revela, por un lado, la incapacidad de las autoridades para controlar a esos actores y por otro, la capacidad de estos para moverse por diferentes espacios sociocuturales.

Este tipo de categorías estigmáticas ha llevado a suponer que los sujetos a que referían no poseían una sociabilidad y que se mantenían completamente al margen del ejercicio de la "acción política" (Coni, 1969). Los estudios más recientes conciben esta realidad bajo una nueva luz y revisan la perspectiva tradicional por medio de la búsqueda de indicios que permiten reconstruir una sociabilidad de la campaña con una lógica propia (Bracco, 2003; Garavaglia, 1997; Garavaglia; Gelman, 1995; Rodriguez Molas, 1994; Zurutuza, 1994).

Ya he referido cómo se generaban algunos de los espacios de ambigüedad. Ahora describiré brevemente algunas de las prácticas socioculturales que definían la dinámica de estos actores fronterizos.

\section{Vacas, caballos y mujeres}

El robo de ganado es una de las prácticas delictivas probablemente más enfatizada por la historiografía como característica de la "gente de la campaña" desarraigada. Ciertamente, las inmensas estancias existentes en la zona eran polos de atracción para población proveniente de Rio Grande, la Banda Oriental, Corrientes, Asunción y, claro está, los pueblos guaraní misioneros que conformaron diversos frentes pobladores y entraron en fricción en las tres últimas décadas del siglo XVIII (Bracco, 2003; Wilde, 2001). La apropiación de ganado equino y vacuno era uno de los objetivos de los frecuentes choques de partidas que se produjeron en este período. Generalmente son acusados de esto los "infieles" de quienes se alega que invaden las estancias de los pueblos y se llevan cuanto pueden. El guaraní misionero Abraham Guirado del pueblo de Yapeyú, uno de los más afectados escribe: 
[...] hace años que se hallan las estancias y demás puestos de su Pueblo combatidos de los indios infieles Minuanes en terminos que además de robarles quantas caballadas acopian en aquellos destinos, para el servicio de la gente que se emplea en ellas, matan a los naturales y a los que les dejan con vida les quitan la ropa y cuanto tienen, de suerte que los tiene reducidos a sus hilos en una total consternación y por lo mismo cuando pasan a la recogida de sus ganados al campo les es forzoso caminar con una precaución sobre manera perjudicial a sus intereses, por cuanto el gasto que originan para las expediciones no soportan, con el valor del poco ganado que conducen, esto es aún en aquellas ocasiones que se liberan de ser sorprendidos de los enemigos, pues en los que experimentan cualesquiera encuentro pierden el ganado y la mayor parte de las caballadas. (Guirado, [ca. 1778]).

Quejas como estas se producen hasta bien entrado el siglo XIX. Todavía en 1809 encontramos esfuerzos coordinados entre las autoridades a uno y otro lado del Río Uruguay para detener las tropelías que asolaban a la campaña. Así, el comandante de la frontera portuguesa Chagas Santos escribía al Teniente gobernador español Agustín de la Rosa: "devo ser igualmente interesado em que os habitantes de huma, e outra banda nao sejaó insultados pelos foragidos, e malfeitores". Y a continuación respondía a acusaciones del Teniente contra los portugueses alegando que eran también los españoles los que practicaban "insultos e roubos das Campanhas" (AGN IX.18.3.7).

Hay que destacar que más allá de la visión plasmada en la documentación oficial, las actividades consideradas ilegales generaban gran cantidad de espacios de sociabilidad y categorías de pertenencia integrando a numerosas personas que supuestamente vagaban por los "desiertos". Este ámbito de fronteras indefinidas, personas de diferentes orígenas étnicos establecían circuitos de intercambio material y simbólico que dinamizaban y actualizaban permanentemente sus relaciones sociales. Esto explica en buena medida la abrumadora multiplicación de espacios como las "pulperías" que servían como "postas" a los contrabandistas de cueros por la campaña pero que simultáneamente eran utilizados como lugares de encuentro e intercambio de información y de bienes. Lo mismo puede decirse de los establecimientos de estancia en general, donde se desarrollaba 
toda una vida social y redes reciprocitarias. Allí también surgían y se consolidaban nuevas formas de expresión política, estética y religiosa. ${ }^{19}$

En estos nuevos "espacios de interacción" debe enfatizarse la frecuentemente soslayada dimensión sexual. Para ello vale la pena volver entonces a los indicios que aporta la declaración de la desdichada María Isabel Franco referida más arriba. Según indica su testimonio, el "indio cristiano" Josef Ignacio y sus compañeros "infieles" se encontraban particularmente preocupados por saber sobre la disponibilidad de mujeres en la región de las estancias. Fuentes posteriores permiten constatar que esta preocupación se afianzó con el paso de los años. En fecha tan tardía como 1808, el funcionario Pablo Thompson escribe al Virrey Liniers desde el pueblo misionero de San Carlos que las penas que se imponen a los "naturales" no tienen efecto en su ánimo. Que hurtan, hieren y "roban mugeres casadas", viven amancebados, andan vagos y faltan el respeto a sus párrocos. Agrega que es imposible hacerlos cultivar la tierra que se les ha adjudicado (Thompson [23-10-1808]). Ese mismo año, el sudelegado del pueblo misionero de Yapeyú informaba que una india de La Cruz llamada María Paula Tamay, había sido puesta presa por "doble matrimonio". Luego ordena que esa mujer sea restituida a su marido, José Braulio Torres (Lariz [23-3-1808]). Según informa otro documento del pueblo de Candelaria al año siguiente, una indígena llamada Paula Cuñañandu fue robada por Juan Guarumbaye, artillero de la Unión, que se la llevó con él por el Río Paraná. Esta era esposa del miliciano Gregorio Aripuy de la caballería de los Guaraní. En su compañía, señala el documento, iban "suponiendose esposa de Enrique Cayaré, Maria Silveria Curetu, cuyo marido Venancio Guazucuniá queda en Itapua (AGN IX.18.3.7).

Tanto el "robo de mujeres" como la "promiscuidad sexual" fueron prácticas muy difundidas en el espacio guaraní misionero. ¿Acaso se trataba

${ }^{19}$ El término "estancia" aludía tanto al territorio del pueblo en el que se realizaban las tradicionales "vaquerías" como al establecimiento para la crianza y amansamiento de animales bajo el control y vigilancia de los habitantes del poblado (Barrios Pintos, 1967, 1973; Poenitz, A., 1983). En este segundo sentido se trataba de ámbitos donde podía desarrollarse una vida social relativamente autónoma con respecto a los pueblos a los que estaban sujetas. Además de corrales, galpones y tinglados había en los establecimientos viviendas y huertas para los capataces y operarios y sus familias, "pulperías" y capillas para el desenvolvimiento de actividades sociales y religiosas. Si bien la multiplicación de estos ámbitos respondía a la intensificación de actividades de compra-venta de cueros también cubrían la necesidad de recrear vínculos identitarios y redes reciprocitarias. En ellos se gestaban categorías laborales como "pulpero", "barraquero", "carrero", "marinero", "changador", entre otras que diluían al menos temporariamente los límites étnicos de los sujetos.

Horizontes Antropológicos, Porto Alegre, ano 9, n. 19, p. 105-135, julho de 2003 
de estrategias conscientemente instrumentadas para evadir los controles de las autoridades? Así puede inferirse de un párrafo de la Memoria de Gonzalo de Doblas escrito en 1785:

Los indios que se desertan llevan regularmente alguna india que no es su muger, con la que vive como si lo fuera; y, ya salga de la provincia o se quede en ella, en todas partes pasan por casados porque aque/llos á que se agregan, sean indios ó españoles, solo cuidan de disfrutar de su trabajo, sin reparar en que vivan como cristianos o no. Y así ni procuran que oigan misa, ni el que se confiesen, ni que ejerciten ningun acto de cristianos pues saben que si los quieren obligar á ello se van a otra parte y los dejan: con que, por no privarse del servicio que les hacen los dejan vivir como infieles (Doblas, 18361837, p. 35-36).

Aparentemente esta "promiscuidad" no fue una característica exclusiva de la época postjesuítica como ha querido verse. Ya existen algunas evidencias al respecto en los tiempos jesuitas. La más interesante informa sobre una sublevación de caciques de varios pueblos comandada por un tal Diego Chaupaí en 1735 contra la restricción de elegir mujeres libremente. Los sublevados desertaron de sus pueblos y crearon una colonia en las cercanías del Iberá. El jesuita Nusdorffer brinda algunos datos sobre este pueblo en una carta. La nueva reducción, indica, estaba "enteramente modelada sobre las de Guaraniés" pero en ella prevalecía "la poligamia". Informa que "[c]omo les fracasara la faz económica, se pusieron a robar el ganado correntino hasta que los dueños de éste acabaron con esos disidentes" (Furlong, 1971, p. 121). ${ }^{20}$

En conclusión, puede decirse que los espacios de ambigüedad creados por estos desertores establecían en términos socioculturales una "condición liminar" de gran eficacia para maniobrar más libremente por los resquicios del sistema sin perder completamente referencias y símbolos identitarios de

${ }^{20}$ El original de esta carta se encuentra en la Biblioteca Nacional de Río de Janeiro, Colección de manuscritos de Pedro de Angelis, 1.29.4.59 (Ver E.J.A.M., 1974). La evidencia para el período jesuítico no acaba aquí. Ya las cartas anuas del siglo XVII dan noticias de estrategias parecidas. Hacia la tercera década de ese siglo se informa de un indio que ha convencido a una mujer de huir de su pueblo. Dice el redactor jesuita: "No se comprende cómo podía consentir la india en esto pero el hecho es que se fue con aquel, y vivió cristianamente entre los infieles, aunque la querían obligar repetidas veces a traicionar a Cristo, y a vivir como los gentiles, sus antepasados" (CA, 1984, p. 127). Algunas páginas más adelante se informa de que "[c]ierto cristiano, legítimamente casado, abandonó a su mujer, juntóse con otra, y volvió con ella a su tierra natal [...]" (CA, 1984, p. 134).

Horizontes Antropológicos, Porto Alegre, ano 9, n. 19, p. 105-135, julho de 2003 
la sociedad originaria. Es posible suponer que la dinámica de esos actores, caótica en apariencia, poseía en realidad una lógica de funcionamiento autónoma. Por medio de la generación de espacios de ambigüedad sociocultural, basados en las mezclas e intercambios simbólicos y biológicos, intentaban evadir los controles del Estado. Simultáneamente, definían espacios de sociabilidad y de reciprocidad que por su carácter móvil y flexible no se ajustaban a las disposiciones oficiales y eran a menudo perseguidos por la justicia.

Algunos actores eran muy conscientes de la eficacia de estas opciones frente a la posibilidad de vivir bajo la opresión del régimen colonial. Así lo reconoce un funcionario en relación con los "infieles". Dice de ellos:

[...] no quieren administrar ningún partido de paz que se les propone de parte de los guaranís, por que conceptuan que con mantener la guerra $\mathrm{u}$ hacer hostilidades, consiguen mayores ventajas, por la proposición que tienen de vender las caballadas y ganados a los portugueses, quienes además de pagarles su importe los regalan y agasajan con dádivas por la utilidad y beneficio que les reporta para sus establecimientos [...] (AGN IX.39.5.5).

Se revela en este párrafo una racionalidad que compartía mucha "gente de la campaña". Tanto la guerra, como el contrabando, el abigeato, el cuatrerismo y las faenas clandestinas de cueros entre otras prácticas eran consideradas por esta gente alternativas más ventajosas que la vida estable de un "poblador virtuoso". Permitían rápido acceso a ganados y provisiones, nutrían relaciones reciprocitarias y probablemente también incrementaban el prestigio de algunos actores (Saguier, 1991). Esa racionalidad móvil constituye la base de sustentación de estas personas y una modalidad singular de participación en los procesos regionales que con el tiempo dominará todo la región platina.

\section{A modo de conclusión}

En el presente artículo he aportado datos para reconstruir a grandes líneas dos tendencias socioculturales que se opusieron hacia fines del siglo XVIII. Por un lado, la tendencia ordenadora del discurso oficial con respecto a la población de los dominios coloniales españoles que, apelando 
a la ciencia, creó diferencias socioculturales con el objeto de asimilarlas o exterminarlas posteriormente. Por otro lado, la dinámica concreta de los actores que definió espacios de ambigüedad sociocultural para confundir a las autoridades estatales y escapar de los rígidos controles que se les imponía. En síntesis, una tendencia establecía el orden por medio de dispositivos de clasificación-asimiliación y la otra imponía la ambigüedad por medio de movimientos que rompían con los límites socioculturales rígidamente trazados por el relato dominante.

Subyacen a cada una de estas tendencias ideas contrapuestas de territorialidad. Mientras la visión oficial representaba al territorio como espacio continuo de fronteras fijas, los actores locales lo concebían de manera flexible y móvil. Mientras en el primer caso la idea de territorio está claramente ligada a la existencia de un Estado, en el segundo, se vincula a interacciones concretas que ocurren en el amplio espacio de la campaña, cuyas fronteras son indefinidas. En este territorio discontinuo el Estado es débil como referente identitario. Más bien priman las relaciones interpersonales, los intercambios reciprocitarios y las identidades móviles y ambiguas.

Por debajo de las imágenes y políticas que el Estado empleaba para controlar o reprimir a esta población se desarrollaba toda una gama de prácticas socioculturales autónomas que aún deben ser descubiertas e interpretadas. Quizás esta indagación nos permita reevaluar en el futuro el rol y significado de la "violencia" como forma de hacer "política" en las fronteras de los imperios ibéricos.

\section{Referencias}

ALENCASTRO, Luiz Felipe de. $O$ trato dos viventes: formação do Brasil no Atlântico Sul, séculos XVI e XVII. São Paulo: Companhia das Letras, 2000.

ALONSO, Ana María. The politics of space, time and substance: state formation, nationalism, and ethnicity. Annual Review of Anthropology, n. 23, 1994.

ANES, Gonzalo. Economía e ilustración en la España del siglo XVIII. Madrid: Ariel, 1969.

ANES, Gonzalo. La corona y la América del siglo de las luces. Madrid: Marcial Pons: Asociación Francisco Lopez de Gomara, [s.d.]. 
ARES QUEIJA, Berta; GRUZINSKI, Serge. Entre dos mundos: fronteras culturales y agentes mediadores. Sevilla: Publicaciones de la EEHA, 1997. AZARA, Felix de. Geografía fisica y esférica de las provincias del Paraguay y Misiones guaranies. Montevideo: Anales del Museo Nacional de Montevideo, 1904.

AZARA, Felix de. Viajes por la América Meridional de Don Felix de Azara, Comandante de la comisión de Límites española en la sección del Paraguay: Desde 1789 hasta 1801. Montevideo. Facultad de Humanidades y Ciencias: Instituto de Investigaciones Históricas: Universidad de la República: Biblioteca de Impresos Raros Americanos, 1982.

AZARA, Felix de. Escritos fronterizos. Textos compilados y prologados por Manuel Lucena Giraldo y Alberto Barrueco Rodriguez. Madrid: C.S.I.C. ICONA, 1994.

BAKEWELL, Peter. A history of Latin America : empires and sequels 14501930. Oxford: Blackwell Publishers, 1998.

BARRIOS PINTOS, Aníbal. De las vaquerías al alambrado. Montevideo: Ed. del Nuevo Mundo, 1967.

BARRIOS PINTOS, Aníbal. Historia de la ganadería en el Uruguay: 15741971. Montevideo: Biblioteca Nacional, 1973.

BARTH, Fredrik (Ed.). Ethnic groups and boundaries: the social organization of culture difference. Illinois: Waveland Press, 1998.

BOCCARA, Guillaume; GALINDO, Silvia (Ed.). Lógica mestiza en América. Chile: Instituto de Estudios Indígenas: Universidad de la Frontera, 1999.

BRACCO, Diego. Interaccion sociocultural: genesis de un espacio de frontera y sus influencias en la consolidacion de la Republica Oriental del Uruguay. (Tesis de Tercer Ciclo)-Departamento de Historia de America, Universidad de Sevilla, 2003.

BRIONES, Claudia. La alteridad del "cuarto mundo": una deconstrucción antropológica de la diferencia. Buenos Aires: Ediciones del Sol, 1997.

[CA] Cartas Anuas de la provincia del Paraguay 1637-1639. Ernesto Maeder (Ed.). Buenos Aires: FECIC, 1984.

CAPEL, Horacio. Los diccionarios geográficos de la ilustración española. Barcelona: Cátedra de Geografía Humana, 1981. 
CAPEL, Horacio. Los ingenieros militares en España: siglo XVIII: repertorio biográfico e inventario de su labor científica y espacial. Barcelona: Cátedra de Geografía Humana, 1983.

CELESTINO DE ALMEIDA, Maria Regina. Os indios aldeados no Rio de Janeiro colonial: novos súbditos cristäos do Imperio Português. Tese (Doutorado)-UNICAMP, 2000.

CONI, Emilio. El gaucho: Argentina, Brasil, Uruguay. Buenos Aires: Hachette, 1969.

COUGHLIN, Edward. On the concept of virtue in eighteenth-century Spain. Dieciocho, v. 15, n. 1-2, p. 83-94, 1992.

CHIARAMONTE, José Carlos. Ciudades, provincias, estados: los orígenes de la Nación Argentina (1800-1846). Buenos Aires: Ariel, 1997.

[DA] Diccionario de Autoridades. Diccionario de la lengua castellana en que se explica el verdadero sentido de las voces, su naturaleza y calidad, com las phrases o modos de hablar, los provervios o refranes, y otras cosas convenientes al uso de la lengua. Dedicado a Don Felipe V. Edición facsímil [1726]. Madrid: Real Academia Española: Editorial Gredos: Biblioteca Románica hispánica, 1963.

DE LA GRANJA Y ALVAREZ, Juan [14-9-1770] Carta a Francisco Bruno de Zavala. Jesús 14 de septiembre de 1770. AGN IX.18.5.1.

DOBLAS, Gonzalo de. Memoria histórica, geográfica, política y económica sobre la Provincia de Misiones de indios guaraníes. In: ANGELIS, Pedro de. Colección de obras y documentos relativos a la historia antigua y moderna de las Provincias del Río de la Plata. Buenos Aires: Plus Ultra, 1836-1837. v. 3.

DOBLAS, Gonzalo de. Disertación que trata del estado decadente en que se hallan los pueblos de Misiones y se indican los medios convenientes a su reparación. In: TRENTI ROCAMORA, José Luis. Un Informe inédito de Gonzalo de Doblas sobre la emergente situación de Misiones en 1801. Santa Fé: Departamento de Estudios Coloniales: Castelvi, 1948. p. 21-44.

DOUGLAS, Mary. Pureza y peligro. Madrid: Siglo XXI, 1991.

E.J.A.M. Un desconocido pueblo de desertores guaraníes en el Iberá. 1736. Folia Histórica del Nordeste, n. 1, p. 101-107, 1974.

FURLONG, Guillermo. Bernardo de Nusdorffer y su "Novena Parte" (1760). Buenos Aires: Ediciones Theoria, 1971. 
GARAVAGLIA, Juan Carlos. De "mingas" y "convites": reciprocidad campesina entre los paisanos rioplatenses. Anuario del IEHS, Buenos Aires, n. 12, p. 131-139, 1997.

GARAVAGLIA, Juan Carlos; GELMAN, Jorge. Rural history of the Rio de la Plata, 1600-1850: results of a historiographical renaissance. Latin American Research Review, v. 30, n. 3, p. 75-105, 1995.

GONZÁLEZ, Julio Cesar. Don Felix de Azara: apuntes biobibliográficos. Buenos Aires: Bajel, 1943.

GRUZINSKI, Serge. La pensée métisse. Paris: Fayard, 1999.

GRUZINSKI, Serge; WACHTEL, Nathan (Ed.). Le Nouveau Monde Mondes Nouveaux: l' experience americaine. Paris: Editions Recherche sur les Civilisations, 1996.

GUIRABO, Don Abraham [ca. 1778]) Pueblo de Yapeyú. AGN IX.39.5.5. HERA, Alberto. Iglesia y corona en la América española. Madrid: MAPFRE, 1992.

LASTARRIA, Miguel de. Colonias orientales del Río Paraguay o de la Plata. Buenos Aires: Instituto de Investigaciones Históricas: Facultad de Filosofía y Letras, 1914.

LARIZ, José de [23-3-1808] Pueblo de Santo Tomé, 23 de marzo de 1808. AGN IX.18.3.7.

LORANDI, Ana María; WILDE, Guillermo. Desafío a la isocronía del péndulo. Acerca de la teoría y de la práctica de la antropología histórica. Memoria Americana: Cuadernos de Etnohistoria, Buenos Aires, n. 9, p. 3778, 2000.

MAEDER, Ernesto. Misiones del Paraguay: conflicto y disolución de la sociedad guaraní. Madrid: MAPFRE, 1992.

MARAVALL, José Antonio. Poder, honor y élites en el siglo XVII. Madrid: Siglo XXI, 1989.

MARILUZ URQUIJO, José María. La expedición contra los charrúas en 1801 y la Fundación de Belén. Revista del Instituto Histórico y Geográfico del Uruguay, Montevideo, n. XIX, p. 53-94, 1952.

NUSDORFFER, Bernardo. Novena parte de lo sucesido en las Doctrinas el año 1760, en orden a la transmigración de los 7 pueblos del Uruguay, y su entrega a la corona de Portugal, por el tratado de límites. In: FURLONG, 
Guillermo. Bernardo de Nusdorffer y su "Novena Parte" (1760). Buenos Aires: Ediciones Theoria, 1971.

ORTIZ, Marcos [7-11-1768] Carta de Fray Marcos Ortiz al Gobernador. Yapeyú, 7 de noviembre de 1768. AGN IX.6.10.7.

PAGDEN, Anthony. The fall of Natural Man: the American Indian and the origins of comparative ethnology. Cambridge: Cambridge University Press, 1982.

PAGDEN, Anthony. Spanish imperialism and the political imagination: studies in European and Spanish-American social and political theory 15131830. New Haven: Yale University Press, 1990.

PAGDEN, Anthony. Lords of all the World: ideologies of Empire in Spain, Britain and France. New Haven: Yale University Press, 1995.

PÉREZ, Francisco [12-12-1770] carta al gobernador, 12 de diceimbre de 1770. AGN IX.18.5.1.

PIETSCHMANN, Horst (Ed.). Atlantic History: History of the Atlantic System 1580-1830. Göttingen: Vandenhoeck \& Ruprecht, 2002.

PITT-RIVERS, Julian; PERISTIANY, J. G. (Ed.). Honor y gracia. Madrid: Alianza, 1993.

PODGORNY, Irina; SCHÄFFNER, Wolfgang. "La intención de observar abre los ojos": narraciones, datos y medios técnicos en las empresas humboldtianas del siglo XIX. Prismas: Revista de historia intelectual, Buenos Aires, n. 4, p. 217-227, 2000.

POENITZ, Alfredo. La economía del Yapeyú Postjesuítico. In: ENCUENTRO DE GEOHISTORIA REGIONAL, 4. Insituto de Investigaciones Geohistóricas. Resistencia (Chaco), 1983.

POENITZ, Edgar. Los infieles minuanes y charrúas en el territorio misionero durante la época virreinal. In: ENCUENTRO DE GEOHISTORIA REGIONAL, 6. Posadas: Facultad de Ciencias Sociales/ Universidad Nacional de Misiones, 1985.

POENITZ, Edgar; POENITZ, Alfredo. Misiones, provincia guaranítica: defensa y disolución (1768-1830). Posadas: Ed. Universitaria/UNAM, 1993.

PORTO, Aurelio. História das Missoes orientais do Uruguai. Rio de Janeiro: Imprenta Nacional, 1943. 
PRATT, Mary Louis. Ojos imperiales: literatura de viajes y transculturación. Buenos Aires: Universidad Nacional de Quilmes, 1997.

QUIJADA, Mónica; BERNAND, Carmen; SCHNEIDER, Arnd. Homogeneidad y Nación: con un estudio de caso: Argentina siglos XIX y XX. Madrid: Consejo Superior de Investigaciones Científicas, 2000.

RATTO, Silvia. El delicado equilibro de la convivencia fronteriza. Buenos Aires 1830-1850. In: JORNADAS INTER-ESCUELAS Y/O DEPARTAMENTOS DE HISTORIA, 8., 2001, Salta.

RODRÍGUEZ MOLAS, Ricardo. Historia Social del gaucho. Buenos Aires: Centro Editor de América Latina, 1994.

SAGUIER, Eduardo. El mercado del cuero y su rol como fuente alternativa de empleo: el caso del trabajo a destajo en las vaquerías de la Banda Oriental durante el siglo XVIII. Revista de Historia Económica, v. 9, n. 1, p. 103-126, 1991.

SAN PÍO, M. P. de. Expediciones del siglo XVIII. Madrid: MAPFRE, 1992. SCHWARTZ, Stuart. Implicit understandings: observing, reporting, and reflecting on the econunters between Europeans and other peoples in the Early Modern Era. New York: Cambridge University Press, 1994.

SIDER, Gerald. When parrots learns to talk, and why they can't: domination, deception, and self-deception in Indian-White relations. Society for Comparative Study of Society and History, 1987.

THOMPSON, Pablo [23-10-1808] Carta al virrey Liniers, Pueblo de San Carlos, 23 de octubre de 1808. AGN IX.18.3.7.

URBAN, Greg. Two faces of culture. Working Papers and Proceedings of the Center of Psychosocial Studies, Chicago, n. 49, p. 1-21, 1992.

WEBER, David. Borbones y Bárbaros: centro y periferia en la reformulación de la política de España hacia los indígenas no sometidos. Anuario IEHS, Buenos Aires, n. 13, p. 147-173, 1998.

WILDE, Guillermo. ¿Segregación o asimilación?: la política indiana en América Meridional a fines del período colonial. Revista de Indias, Madrid, v. 59, n. 217, p. 619-644, 1999.

WILDE, Guillermo. Los guaraníes después de la expulsión de los jesuitas: dinámicas políticas y prácticas simbólicas. Revista Complutense de Historia de América, Madrid, n. 27, p. 69-109, 2001. 
ZAVALA, Francisco Bruno [28-12-1768] Carta al Gobernador. Pueblo de la Cruz a 28 de Diz de 1768. AGN IX.6.10.7.

ZAVALA, Francisco Bruno [9-2-1769] Carta al gobernador. Pueblo de Yapeyú a 9 de febrero de 1769. AGN IX.18.5.1.

ZAVALA, Francisco Bruno [17-9-1770] Carta al gobernador. Candelaria 17 de setiembre de 1770. AGN IX.18.5.1.

ZURUTUZA, Roberto. Frontera, abigeato y bandolerismo: la mesopotamia durante el período colonial tardía (1770-1810). Tesis (Licenciatura)-Departamento de Ciencias Antropologicas/FFyL/UBA, Buenos Aires, 1994.

Abreviaturas

AGN: Archivo General de la Nación (Argentina)

ANA (SH): Archivo Nacional de Asunción. Sección Histórica.

Recebido em 06/05/2003

Aprovado em 30/05/2003 